\title{
Implicit motives and basic need satisfaction in extreme endurance sports
}

\author{
Schüler, Julia ; Wegner, Mirko ; Knechtle, Beat
}

\begin{abstract}
Previous research has shown that the effects of basic psychological needs on the flow experience in sports are moderated by implicit motives. However, so far, only leisure and health-oriented sports have been analyzed. In a pilot study and a main study $(\mathrm{N}=29,93)$, we tested whether the implicit achievement and affiliation motives interact with the need for competence and the need for social relatedness satisfaction, respectively, to predict flow experience and well-being in extreme endurance athletes. Results showed that highly achievementmotivated individuals benefited more from the need for competence satisfaction in terms of flow than individuals with a low achievement motive did. In addition, highly affiliation-motivated individuals whose need for social relatedness is satisfied reported higher positive affect and lower exercise addiction scores than athletes with a low motive. We discuss the differential effects of the interplay between the achievement and affiliation motives and basic needs on different outcome variables.
\end{abstract}

DOI: https://doi.org/10.1123/jsep.2013-0191

Posted at the Zurich Open Repository and Archive, University of Zurich

ZORA URL: https://doi.org/10.5167/uzh-96690

Journal Article

Published Version

Originally published at:

Schüler, Julia; Wegner, Mirko; Knechtle, Beat (2014). Implicit motives and basic need satisfaction in extreme endurance sports. Journal of Sport Exercise Psychology, 36(3):293-302.

DOI: https://doi.org/10.1123/jsep.2013-0191 


\title{
Implicit Motives and Basic Need Satisfaction in Extreme Endurance Sports
}

\author{
Julia Schüler, ${ }^{1}$ Mirko Wegner, ${ }^{1}$ and Beat Knechtle ${ }^{2}$ \\ ${ }^{1}$ University of Bern; ${ }^{2}$ University of Zurich
}

\begin{abstract}
Previous research has shown that the effects of basic psychological needs on the flow experience in sports are moderated by implicit motives. However, so far, only leisure and health-oriented sports have been analyzed. In a pilot study and a main study $(N=29,93)$, we tested whether the implicit achievement and affiliation motives interact with the need for competence and the need for social relatedness satisfaction, respectively, to predict flow experience and well-being in extreme endurance athletes. Results showed that highly achievement-motivated individuals benefited more from the need for competence satisfaction in terms of flow than individuals with a low achievement motive did. In addition, highly affiliation-motivated individuals whose need for social relatedness is satisfied reported higher positive affect and lower exercise addiction scores than athletes with a low motive. We discuss the differential effects of the interplay between the achievement and affiliation motives and basic needs on different outcome variables.
\end{abstract}

Keywords: implicit motives, basic psychological needs, motive dispositions, self-determination theory, extreme endurance sports

Whereas most people may know someone who has run a marathon or may even have run a marathon themselves, people who engage in extreme endurance sports are relatively rare. Even endurance sports athletes might wonder what motivates a person to run $100 \mathrm{~km}$ (rather than $42.19 \mathrm{~km}$ in a marathon), to perform a multiple triathlon, or to spend several days in a row on a bicycle. In the present research, we analyzed the predictors of positive "activators," such as flow experience and positive affect, while people are engaging in endurance sport. In addition, we tested exercise addiction, which is a negative driving force as well as an indicator of the absence of well-being in sport. Basic needs like the experience of social relatedness and competence (Deci \& Ryan, 1985, 2000) and implicit motives are strongly linked to human behavior (McClelland, 1985). We therefore referred to previous research, according to which the satisfaction of basic psychological needs, a concept within selfdetermination theory (SDT; Deci \& Ryan, 1985, 2000), fosters aspects of motivation in sports (e.g., Edmunds, Ntoumanis, \& Duda, 2006; Wilson, Rodgers, Blanchard, \& Gessell, 2003). In addition, we considered implicit motives (McClelland, 1985; Schultheiss \& Brunstein,

Julia Schüler and Mirko Wegner are with the Institute of Sport Science, University of Bern, Bern, Switzerland. Beat Knechtle is with the Institute of General Practice and Health Services Research, University of Zurich, Zurich, Switzerland. Address author correspondence to Julia Schüler at julia.schueler@ ispw. unibe.ch.
2010) because they have been found to function as moderators of the relationship between basic need satisfaction and sport-relevant outcomes in recreational and leisureoriented sports (Schüler \& Brandstätter, 2013; Schüler, Sheldon, \& Fröhlich, 2010).

\section{The Effects of Basic Psychological Needs in Sports}

Within SDT (Deci \& Ryan, 1985, 2000), basic psychological need theory postulates three innate psychological needs "that appear to be essential for facilitating optimal functioning of the natural propensities for growth and integration, as well as for constructive social development and personal well-being" (Ryan \& Deci, 2000, p. 68). These are the needs for autonomy, competence, and social relatedness. Need for autonomy refers to the experience of choice, ownership of behavior, and psychological freedom. Need for competence means experiencing effectance when desired outcomes are attained. Need for social relatedness means caring for others and being cared for and feeling emotionally connected to other people.

Previous research has convincingly confirmed the importance of basic need satisfaction for people's motivation, well-being, and health in a broad variety of life domains (Ryan \& Deci, 2000; Vansteenkiste, Niemiec, $\&$ Soenens, 2010). In sports, need satisfaction has been found to foster different aspects of motivation, such as self-determined regulation (Edmunds et al., 2006), intrinsic motivation and flow (Schüler et al., 2010), and 
exercise behavior (Wilson et al., 2003). Need satisfaction also enhances well-being while engaging in sports (Adie, Duda, Ntoumanis, 2008, 2012; Reinboth \& Duda, 2006).

SDT researchers conceptualize basic needs as being innate and universal requirements for one's well-being and psychological growth (Ryan \& Deci, 2000). This implies that basic need satisfaction and basic need thwarting have the same positive and negative effects for all human beings. In accordance with this, cross-cultural studies have shown need satisfaction to have positive effects on people living in individualistic as well as collectivistic cultures (Luyckx, Vansteenkiste, Goossens, \& Duriez, 2009). However, other studies have shown that the effects of basic need satisfaction depend on the correspondence with stable dispositions, called implicit motives (Schüler \& Brandstätter, 2013; Schüler et al., 2010).

\section{The Influence of Implicit Motives on Basic Need Satisfaction Effects}

Implicit motive researchers (Brunstein, 2008; McClelland, 1985; McClelland, Koestner, \& Weinberger, 1989; Murray, 1938; Schultheiss \& Brunstein, 2010) assume that individuals differ in the strength of relatively stable motives due to different learning histories in early childhood. They have mainly focused on three implicit motives. The achievement motive is defined as a recurrent concern with surpassing standards of excellence (McClelland, Atkinson, Clark, \& Lowell, 1953), the affiliation motive is the recurrent concern with building up and maintaining stable and friendly interpersonal relations (French \& Chadwick, 1956), and the power motive is the desire to influence and control other people (Winter, 1973). These motives represent the "capacity to experience the attainment of a certain type of incentive as rewarding; as a consequence, it orients the individual towards cues related to the incentive and energizes, and selects behavior aimed at incentive attainment" (Schultheiss \& Hale, 2007, p. 13).

Implicit motives have to be distinguished from explicit motives (McClelland et al., 1989), which are motivational dispositions that persons consciously ascribe to themselves and thus can easily be measured using self-reports. In contrast, implicit motives operate outside a person's conscious awareness and thus have to be assessed indirectly, for example using an exercise in which participants have to write stories about pictures. Afterward, the experimenters score these stories for motive imagery (Picture Story Exercise, Schultheiss \& Pang, 2007; see measures section).

Schüler and colleagues have taken an integrative approach to the concepts of basic needs and implicit motives to enhance the predictability of motivation and well-being in learning contexts, at the work-place, and in sports (Schüler \& Brandstätter, 2013; Schüler, Brandstätter, \& Sheldon, 2013; Schüler et al., 2010). In line with the principle of implicit motive research, that individuals differ in their preference for incentives (McClelland,
1985) and in their "capacity to experience the attainment of a certain type of incentive as rewarding" (Schultheiss \& Hale, 2007, p. 13), the authors propose that individuals with a strong motive can be presumed to have a greater tendency to benefit from corresponding feelings. Thus, they function as moderators of the need satisfactionoutcome relationship. More specifically, we assume that, compared with individuals with lower motive strengths, individuals with a high achievement motive benefit more from feelings of competence, and individuals with a high affiliation motive benefit more from feelings of being socially related to others. Broader conceptual differences exist between the need for autonomy and the power motive (for a more detailed discussion, see Schüler et al., 2010). Summing up, we assume that implicit motives moderate the effects of the corresponding need satisfaction on a variety of outcome variables.

\section{The Matching Hypothesis of Basic Needs and Motives}

The results of the studies by Schüler et al. (Schüler \& Brandstätter, 2013; Schüler et al., 2010) support this "matching hypothesis," according to which the satisfaction of a basic need must match a person's implicit motive to fully unfold its positive effect on flow and well-being in sports (for a detailed discussion of the confirmation of the universal and matching hypotheses, see Schüler et al., 2013). The authors have shown, for example, that participants of university sport courses that provide a high satisfaction of their basic need for competence experience more flow than individuals with a low need for competence satisfaction (Schüler, et al., 2010). However, a differential effect was revealed when the implicit achievement motive was considered. Individuals with a high achievement motive who felt competent reported more flow than individuals who did not feel competent or had a low achievement motivation. This effect was replicated in correlative and experimental studies, using samples of badminton players and a volleyball exercise for beginners (Schüler et al., 2010). Furthermore, the same effect was demonstrated in the affiliation domain (Schüler \& Brandstätter, 2013, Studies 3 and 4): Highly affiliation-motivated participants of university fitness courses and members of sports clubs reported more flow in sports when their need for social relatedness was satisfied than individuals with a low affiliation motive. To sum up, the beneficial effects of need satisfaction in sports are stronger for individuals with a high corresponding implicit motive.

\section{Present Research}

Although previous research has shown that implicit motives moderate the effects of basic need satisfaction on flow experience in sports, the conclusiveness of these studies is limited because their samples have consisted of persons who mainly engage in recreational and healthoriented sports. What we do not yet know is whether 
the implicit motive $\times$ basic need interaction also holds true for performance-oriented sports. That is why the focus of the present research is on extreme endurance sports athletes.

As in previous studies, we assessed flow experience as a dependent variable because it is a prototype of intrinsic motivation, which helps leisure- and health-oriented as well as achievement-oriented athletes to initiate and maintain physical activity and sport. Flow experience is mainly characterized by an intense experiential involvement in the activity (Csikszentmihalyi, 1990), which leads to a merging of action and awareness, a high sense of control, and an altered sense of time. It is accompanied by a positive quality of the experience and is associated with emotional well-being in different life domains (e.g., Csikszentmihalyi \& LeFevre, 1989; Rheinberg, Manig, Kliegl, Engeser \& Vollmeyer, 2007; Schüler, 2007), among them sports (Jackson, Ford, Kimiecik, \& Marsh, 1998).

Another aspect on which we aim to shed light with the present research is whether the implicit motive $\times$ basic need interaction not only predicts intrinsic motivation but also predicts different facets of well-being in sport. To capture different aspects of well-being, we chose positive affect in sport to cover a general quality of emotional well-being. Furthermore, we measured exercise addiction to capture an aspect of well-being that is more specific to endurance sports. Exercise addiction is defined as "a craving for leisure-time physical activity, resulting in uncontrollable excessive exercise behavior that manifests in physiological and/or psychological symptoms" (Hausenblas, \& Downs, 2002, p. 90). In the long run, it impairs not only emotional well-being but also social well-being and a person's physical health.

We hypothesized that the relationships between basic need for competence and relatedness satisfaction and the respective dependent variables (flow experience, positive affect, exercise addiction) are moderated by the corresponding implicit motives. More specifically, we assumed that the achievement motive interacts with need for competence satisfaction, and the affiliation motive interacts with need for relatedness satisfaction.

We tested our hypotheses in a pilot study with a small number of extreme endurance sport athletes and aimed to replicate the results in a study with a larger sample (main study). For both studies, ethical approval was obtained from the first author's institution review board.

\section{Pilot Study}

\section{Method}

\section{Participants and Procedure}

We recruited 29 ultraendurance athletes (long-distance runners, triathletes, long-distance bikers; 24 men) with a mean age of 47.5 years $(S D=7.85)$ via the mailing lists for ultraendurance events and through personal contacts. The participants' countries of origin were Germany, Switzerland, and Austria, and they had participated in at least one ultraendurance event (defined as a competition that exceeds $6 \mathrm{hr}$ in duration; Zaryski \& Smith, 2005) in the last 2 years (inclusion criterion). Participants filled in a Web survey. It started with a written description of the procedure, and participants provided their informed consent to take part in the study. The Web survey included the implicit motive, the basic need satisfaction, the flow, and affect measures. In addition, we asked participants their age and gender.

\section{Measures}

We assessed the implicit achievement and affiliation motives using the Picture Story Exercise (PSE, Murray, 1943; Schultheiss \& Pang, 2007), which is frequently applied in implicit motive research $(\mathrm{McClelland}$ et al., 1989; see also Schultheiss, Liening, \& Schad, 2008). Previous research has revealed the PSE to be a valid measure of implicit motives (for an overview, see Schultheiss \& Pang, 2007). To name but a few examples, as theoretically expected, implicit motives measured using the PSE were related to performance measures (rather than to choices and judgment as explicit motives; Brunstein \& Hoyer, 2002; deCharms, Morris, Reitman, \& McClelland, 1955), responded to nonverbal cues (better than to verbal cues) and had an impact on nondeclarative measures of motivation (Schultheiss, 2001). They were related to attentional processes, such as attentional orientation to facial expressions signalizing dominance and affiliation (Schultheiss \& Hale, 2007), and were correlated with physiological and health variables (e.g., PSE power motive and basal testosterone levels, Schultheiss et al., 2005; PSE affiliation motive and lower blood pressure, McClelland, 1979). A discussion about different operationalizations of reliability and their appropriateness to evaluating the PSE is presented in Schultheiss et al., 2008. For example, the internal consistency operationalized by Cronbach's $\alpha$ was low, whereas motive scores displayed substantial ipsative stability as assessed by averaged intraindividual correlations between picture profiles across testing occasions (Schultheiss et al., 2008).

Our participants were instructed to look at pictures and then write an imaginative story with a beginning, middle, and end. They were asked to describe who the people in the pictures are, what they are thinking and feeling, and how the story will end. Each picture was displayed for a period of $20 \mathrm{~s}$, after which a text box appeared in which participants typed their stories (for computer applications of the PSE, see also Schultheiss \& Pang, 2007). This procedure was repeated for the subsequent pictures. In the present research, we used six pictures: boxer, couple by the river, ship's captain, women in a laboratory, nightclub scene, and trapeze artists.

Two experienced raters coded the participants' stories for achievement and affiliation motive content 
using Winter's (1994) scoring manual for running text. They achieved high interrater reliabilities of .84 for the achievement motive and .89 for the affiliation motive. Due to high correlations between the achievement motive $(M=2.0, S D=1.77)$ and the affiliation motive scores $(M=3.07, S D=1.46)$ with the number of words in the stories (achievement: $r=.69, p<.001$; affiliation: $r=$ $.69, p<.001)$, the motive scores were residualized for word count.

The satisfaction of basic psychological needs was measured using Sheldon and Hilpert's Balanced Measure of Psychological Needs Scale (Sheldon \& Hilpert, 2012). This comprises six items for each of the basic needs (e.g., competence: I took on and mastered hard challenges; social relatedness: I felt a sense of contact with people who care for me, and for whom I care), which participants answered with reference to their sport context using a 7-point rating scale ranging from 1 (strongly disagree) to 7 (strongly agree). Cronbach's alpha was high for competence $(\alpha=.87)$ and relatedness $(\alpha=.80)$.

We assessed flow experience using the Flow Short Scale (Rheinberg, Vollmeyer, \& Engeser, 2003). Participants were asked to refer to their sport activity on a 7-point scale ranging from 1 (not at all) to 7 (very much) using 10 items (e.g., "I am totally absorbed in what I am doing," "I don't notice time passing"). Reliability for the Flow Short Scale was sufficiently high with $\alpha=.91$.

We used a German version of the Positive and Negative Affect Schedule (Krohne, Egloff, Kohlmann, $\&$ Tausch, 1996) to assess positive affect. Participants rated 10 items (e.g., excited, strong, active) according to how strongly they experience them while performing their sport ( $1=$ very slightly or not at all to $5=$ extremely; $\alpha=.93$ ).

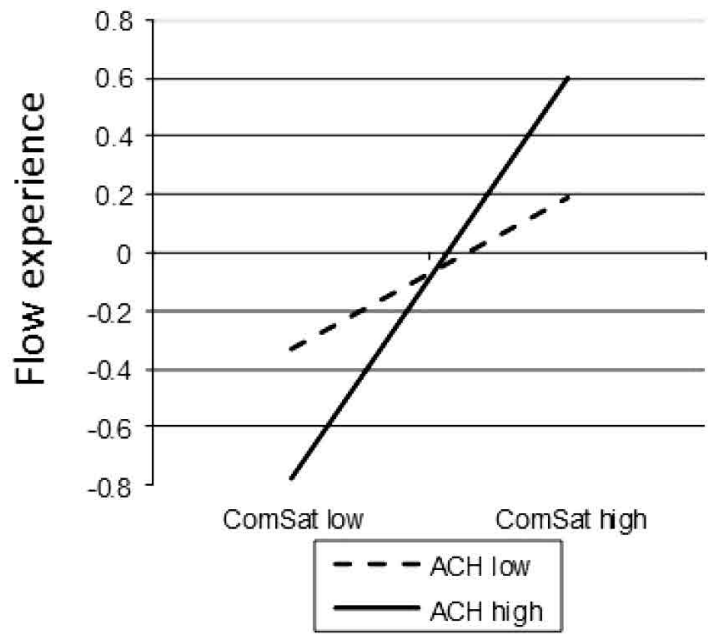

\section{Results and Brief Discussion Descriptive Statistics and Correlations}

Correlational analyses (Pearson, two-tailed) showed that the implicit achievement motive (residualized score: $M=$ $-0.05, S D=1.25$ ) and the affiliation motive (residualized score: $M=0.26, S D=1.00)$ were unrelated to each other and to any of the other variables. Need for competence satisfaction $(M=5.24, S D=1.42)$ was significantly correlated with need for social relatedness satisfaction $(M$ $=5.33, S D=1.15), r=.46, p<.05$, with flow $(M=5.43$, $S D=1.22), r=.44, p<.05$, and with positive affect $(M$ $=3.76, S D=.86), r=.42, p<.05$. Flow and positive affect were significantly related, $r=.46, p<.05$. All other correlations failed to achieve significance. ${ }^{1}$ Neither the participants' age nor their sex was significantly correlated with the assessed variables, nor did these variables influence the results reported below.

Test of Motive $\times$ Need Interaction. A hierarchical regression analysis was conducted, with implicit achievement motive (ACH) and need for competence satisfaction (ComSat) entered into the regression equations as a first step and the $\mathrm{ACH}-\mathrm{ComSat}$ interaction entered as a second step, to predict the flow experience (predictors were $z$-transformed). The main effect for ComSat, $b=.48, s e_{\mathrm{b}}=.19, p=.02$, as well as the ACHComSat interaction were significant, $\Delta R^{2}=.13, b=.21$, $s e_{\mathrm{b}}=.10, p=.04$. To explore the nature of this interaction, we employed a procedure proposed by Cohen, Cohen, West, and Aiken (2003) and entered values one standard deviation above and below the mean of our predictor (need satisfaction) and moderator (implicit motive) into the regression equation. Figure 1 (left side) displays the nature of the interaction.

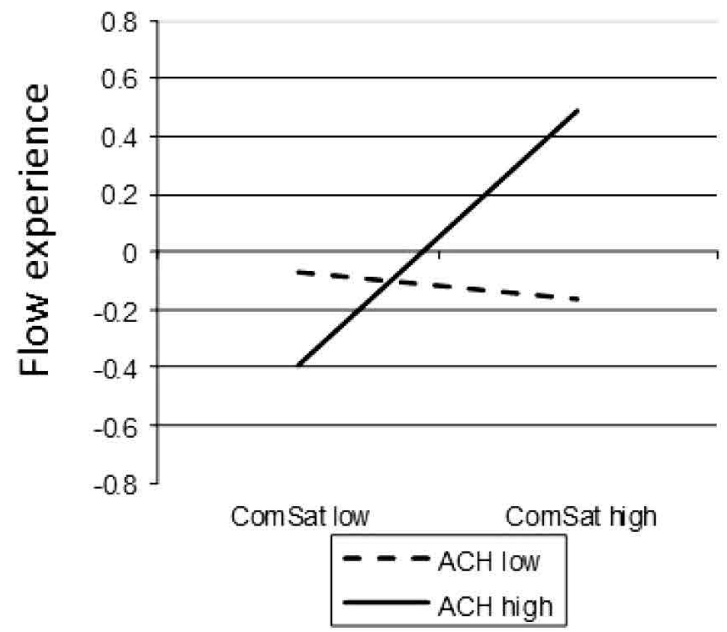

Figure 1 - Illustration of the achievement motive (ACH) — need for competence satisfaction (ComSat) interaction on flow experience in the pilot study (left side) and in the main Study 2 (right side). 
The hierarchical regression analysis that was conducted to predict positive affect revealed a significant main effect for ComSat, $b=.37, s e_{\mathrm{b}}=.17, p=.04$, but not a significant effect for the ACH-ComSat interaction, $\Delta R^{2}$ $=.09, b=.13, s e_{\mathrm{b}}=.09, p=.14$. Two further hierarchical regression analyses tested the hypotheses in the affiliation domain (step 1: affiliation motive, AFF; need for relatedness, RelSat; step 2: AFF-RelSat interaction). Neither the effect of need for relatedness, $b=.16, s e_{\mathrm{b}}=.28, p=.58$, nor the AFF-RelSat interaction, $\Delta R^{2}=.03, b=.26, s e_{\mathrm{b}}$ $=.31, p=.40$, predicted flow experience significantly. However, the AFF-RelSat interaction was a significant predictor of positive affect, $\Delta R^{2}=.17, b=.52, s e_{\mathrm{b}}=.24$, $p=.05$. Figure 2 (left side) illustrates the interaction.

The achievement motive and need for competence interaction predicted flow (but not positive affect), whereas the affiliation motive and need for relatedness interaction predicted positive affect (but not flow). However, due to the small sample size of the pilot study, it was not possible to control for other variables, such as participants' training intensities, which might have influenced the results. The small sample size is also problematic when interpreting complex interactions. Thus, we designed the following study to overcome this limitation.

\section{Main Study}

In this study we used a larger sample of extreme endurance sports athletes. In addition, we assessed another aspect of well-being, namely exercise addiction, to capture a purely sport-specific measure of (the absence) of well-being. Hausenblas and Downs (2002, p. 90) defined exercise addiction as "a craving for leisure-time physical activity, resulting in uncontrollable excessive exercise behavior, that manifests itself in physiological (e.g., tolerance/withdrawal) and/or psychological (e.g., anxiety, depression) symptoms." Although the authors are talking about behavior addiction rather than substance addiction, very similar symptoms are discussed, including salience (exercising becomes the most important activity in one's life), tolerance (increasing amounts of exercising are required), mood modification (exercising as a coping strategy), withdrawal symptoms (e.g., moodiness, irritability), relapse (repeated reversion to earlier exercise patterns after having stopped exercising), and interpersonal and intrapsychic conflicts (Griffiths, 1996; Terry, Szabo, \& Griffiths, 2004). In a nutshell, exercise addiction leads to a severe impairment of a person's overall well-being.

We hypothesized that the implicit achievement motive moderates the effects of basic need for competence satisfaction and that the implicit affiliation motive moderates the effects of basic need for relatedness on flow and the absence of well-being (exercise addiction). Again, we assumed that individuals with a high implicit achievement and affiliation motive benefit more from the corresponding need satisfaction in terms of high flow experience and low impairment of well-being, but also suffer more from the corresponding need frustration in terms of low flow and high impairment of well-being than individuals with low implicit motives.

\section{Method}

\section{Participants and Procedure}

We recruited achievement sports athletes (endurance sports) using the same recruitment strategies and inclusion criteria as in the pilot study. Ninety-three Germanspeaking long-distance runners $(N=73$ men $)$ with a mean age of 47.7 years $(S D=9.46$; mainly from Germany, Switzerland, Austria) participated. They first provided their informed consent to take part in the study and then filled in the implicit motive, the basic need satisfaction,
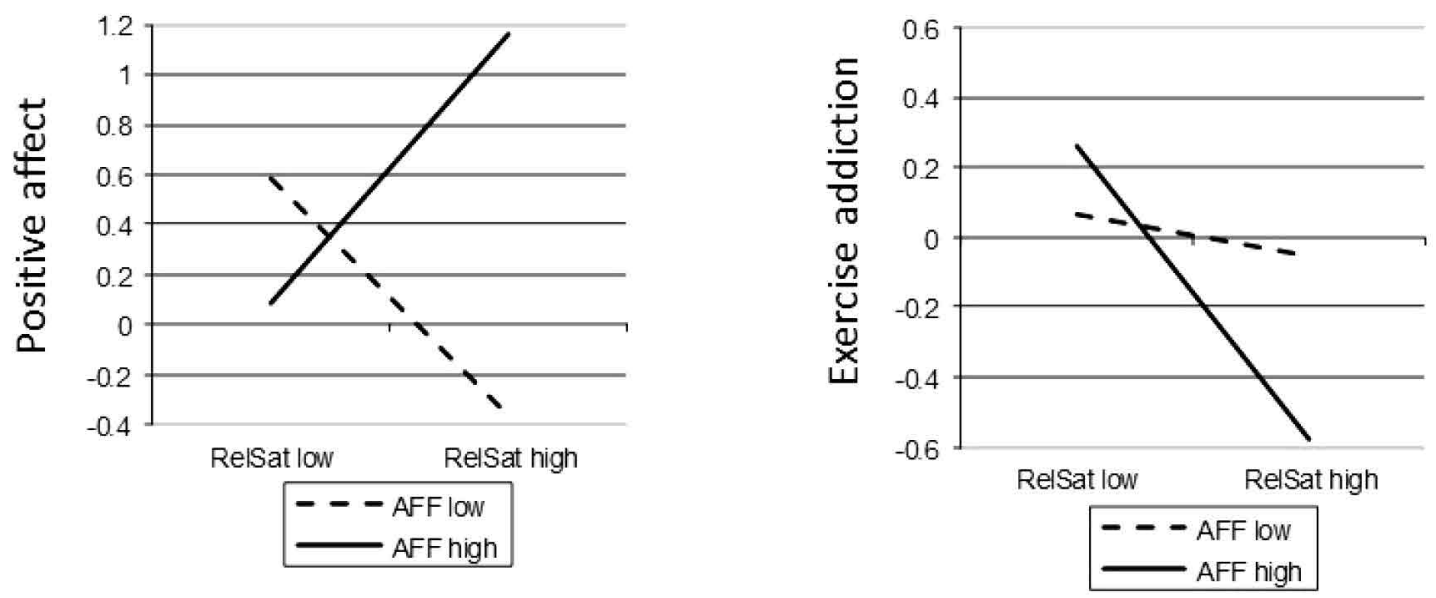

Figure 2 - Illustration of the affiliation motive (AFF)—need for relatedness satisfaction (RelSat) interaction on positive affect (pilot study, left side) and on exercise addiction (main study, right side). 
the flow and the exercise addiction measure. Furthermore, we asked participants about their training intensity, age, and gender.

\section{Measurement}

The implicit achievement $(M=1.57, S D=1.14)$ and affiliation motives $(M=2.09, S D=1.40)$, basic need satisfaction (competence: $M=5.41, S D=1.00, \alpha=.74$; relatedness: $M=5.13, S D=1.13, \alpha=.86)$, and flow experience $(M=5.34, S D=1.06, \alpha=.71)$ were assessed as in the pilot study. Implicit motives were coded by an experienced rater, who had an interrater agreement of $95 \%$ with the prescored material by Winter (1994). Again, residualized motive scores (achievement: $M=-.005, S D$ $=.94$; affiliation: $M=-.012, S D=.99$ ) were used due to high correlations with protocol length (achievement: $r=$ $.33, p<.01$; affiliation: $r=.65, p<.001)$.

Exercise addiction was measured using the Exercise Addiction Inventory (Terry et al., 2004). Participants indicated their agreement with different facets of addiction (e.g., withdrawal symptoms: If I have to miss an exercise session, Ifeel moody and irritable; tolerance: Over time I have increased the amount of exercise I do in a day) using a scale ranging from 1 (strongly disagree) to 5 (strongly agree). Participants achieved a mean score of $M=3.94$ $(S D=1.08 ; \alpha=.68)$. We assessed training intensity by asking participants about their average number of training hours per week.

\section{Results and Brief Discussion}

\section{Preliminary Analyses, Descriptive Statistics, and Correlations}

Independent sample $t$ tests revealed that men and women differed marginally in their achievement motive (residualized score; men: $M=-.11, S D=.89$; women: $M=.38$, $S D=1.04), t(91)=1.91, p=.07$, with women reporting higher scores than men. ${ }^{2}$
Table 1 shows the correlations between the assessed variables. The participants' age was negatively related to their training intensity and at least marginally positively related to their need for competence satisfaction, need for relatedness satisfaction, and flow experience. Age was negatively, whereas training intensity was positively, related to exercise addiction.

Again, the achievement and affiliation motive were unrelated. The achievement motive was significantly related to relatedness satisfaction. Basic need for competence and relatedness satisfaction were associated with each other on a highly significant level and additionally displayed significant positive relationships with flow experience. Furthermore, need for relatedness and exercise addiction were significantly negatively related. ${ }^{1}$

\section{Test of Motive $\times$ Need Interaction}

Achievement Motive and Need for Competence. We conducted the same hierarchical regression analyses as in the pilot study to predict flow experience (step 1: $\mathrm{ACH}$, ComSat; step 2: ACH $\times$ Comsat). Again, the main effect for ComSat, $b=.20$, $s e_{\mathrm{b}}=.10, p=.05$, and the ACHComSat interaction were significant, $\Delta R^{2}=.05, b=.24$, $s e_{\mathrm{b}}=.11, p=.03$ (see right side of Figure 1). Because age correlated significantly with the dependent variable, we used it as a control variable in a supplementary analysis. The result was quite similar and the interaction effect remained significant, $\Delta R^{2}=.05, b=.26, s e_{\mathrm{b}}=.12, p=.03$.

The analysis predicting exercise addiction (step 1: $\mathrm{ACH}, \mathrm{ComSat}$; step 2: $\mathrm{ACH} \times$ Comsat) revealed no significant main effects or a significant $\mathrm{ACH}-\mathrm{ComSat}$ interaction effect, $\Delta R^{2}=.009, b=.11, s e_{\mathrm{b}}=.11, p=.36$. This is also true when the participants' age and training intensity are used as control variables due to significant correlations with exercise addiction, (interaction effect: $\left.\Delta R^{2}=.005, b=.08, s e_{\mathrm{b}}=.11, p=.47\right)$.

Affiliation Motive and Need for Relatedness. We then conducted additional hierarchical regression analyses in the affiliation domain. A first hierarchical regression

Table 1 Correlation Coefficients (Pearson, two-tailed) Between Variables in Study 2

\begin{tabular}{|c|c|c|c|c|c|c|c|c|c|}
\hline & & 1 & 2 & 3 & 4 & 5 & 6 & 7 & 8 \\
\hline 1 & Age & 1 & $-.30 * *$ & -.04 & -.10 & $.19 \dagger$ & $.26 *$ & $.19 \dagger$ & $-.31 * *$ \\
\hline 2 & Training intensity & & 1 & -.09 & -.03 & -.03 & -.10 & .06 & $.38 * * *$ \\
\hline 3 & $\mathrm{ACH}$ & & & 1 & .02 & .14 & $.22 *$ & .12 & -.02 \\
\hline 4 & AFF & & & & 1 & .07 & .10 & .01 & -.13 \\
\hline 5 & ComSat & & & & & 1 & $.68 * * *$ & $.23^{*}$ & -.14 \\
\hline 6 & RelSat & & & & & & 1 & $.26^{*}$ & $-.24 *$ \\
\hline 7 & Flow & & & & & & & 1 & .10 \\
\hline 8 & Exercise addiction & & & & & & & & 1 \\
\hline
\end{tabular}

Note $. \mathrm{ACH}=$ achievement motive, $\mathrm{AFF}=$ affiliation motive, ComSat $=$ basic need for competence satisfaction, RelSat $=$ basic need for relatedness satisfaction.

$\dagger p<.10 . * p<.05 . * * p<.01 . * * * p<.001$. 
analysis (step 1: AFF, RelSat; step 2: AFF $\times$ RelSat) showed that need for relatedness satisfaction, $b=.25, s e_{\mathrm{b}}$ $=.10, p=.01$, predicted flow experience, but the AFF $\times$ RelSat interaction did not, $\Delta R^{2}=.001, b=-.02, s e_{\mathrm{b}}=$ $.10, p=.84$ (also when controlling for participants' age, $\left.\Delta R^{2}=.001, b=-.01, s e_{\mathrm{b}}=.10, p=.77\right)$.

However, in the analysis to predict exercise addiction (step 1: AFF, RelSat; step 2: AFF $\times$ RelSat), need for relatedness satisfaction, $b=-.24, s e_{\mathrm{b}}=.09, p=.01$, as well as the AFF $\times$ RelSat interaction, $\Delta R^{2}=.04, b=-.18$, $s e_{\mathrm{b}}=.09, p=.05$, were found to be significant predictors. The interaction effect also holds true, although it is a bit weaker, when the control variables age and training intensity are considered, interaction effect: $\Delta R^{2}=.03, b$ $=-.16, s e_{\mathrm{b}}=.08, p=.06$. The interaction is illustrated in Figure 2 (right side).

Summing up, as in the pilot study, the $\mathrm{ACH} \times$ ComSat interaction predicted flow (but not exercise addiction), whereas the AFF $\times$ RelSat interaction predicted the well-being variable exercise addiction (but not flow).

\section{General Discussion}

A pilot study and a study with a larger sample confirmed the results that have so far only been shown to apply to leisure-oriented and recreational sports (Schüler \& Brandstätter, 2013; Schüler et al., 2010). The satisfaction of the basic needs for competence and social relatedness alone did not predict the flow experience and facets of well-being in extreme endurance sports equally for everybody, as is proposed by SDT (Deci \& Ryan, 1985). Instead, we observed an interaction between basic need satisfaction and the respective motive dispositions. Accordingly, in terms of their flow experience, individuals with a high achievement motive benefited more from need for competence satisfaction than individuals with a low achievement motive. Athletes with a high affiliation motive, in turn, reported greater well-being (higher positive affect, lower exercise addiction) when their need for social relatedness was satisfied than individuals with a low affiliation motive.

The studies also revealed that different motive-need interactions predict different outcomes. The achievement motive interacted with competence satisfaction when predicting flow, whereas the affiliation motive interacted with relatedness satisfaction when predicting facets of well-being. Although it is tempting to draw conclusions from and speculate on these results, they should be treated with caution due to the studies' relatively small sample sizes and their correlational design. Future experimental and correlational studies that replicate and explain our studies' results are essential. At this point we can only speculate that the reason that the $\mathrm{AFF} \times$ RelSat interaction was unable to predict flow might be that flow in extreme endurance sports is mainly an achievement-related phenomenon associated with mastery experiences, the need to achieve, enjoyment, and persistence (Nakamura \& Csikszentmihalyi, 2002). This may result in flow being predicted better by achievement-related rather than by socially related variables, as used in our data. However, this does not rule out the possibility that the interaction of the affiliation motive and social relatedness satisfaction can play a crucial role in predicting flow in sports in which social relatedness is more important. Examples are recreation-oriented fitness sports courses, which are partly performed for the sake of spending harmonious leisure time with other people (e.g., Schüler \& Brandstätter, 2013) and team sports in which the harmonious interplay is a defining characteristic (for flow in team sports, see Aube, Brunelle, \& Rousseau, 2014; for flow in nonachievement situations, see Schiepe-Tiska \& Engeser, 2012).

The reason why the $\mathrm{ACH} \times \mathrm{ComSat}$ interaction did not predict positive affect might be that we did not choose an affect that is particularly representative for individuals with a high achievement motive. According to Weinberger and McClelland (1990), the crucial affective incentive for achievement-motivated individuals is the desire to feel excited and interested while meeting a challenge, rather than experiencing positive affect in a more general sense. In contrast, the crucial affective incentive for individuals with a high affiliation motive is an intense feeling of joy, happiness, and pleasure (McClelland, 1985), which is closer to the general positive affect measure we used in the present studies. We expect that future studies that are more motive-specific with regard to the affect measure will reveal the expected interaction effect for the achievement domain too.

The reason why the $\mathrm{ACH} \times \mathrm{ComSat}$ interaction did not predict exercise addiction could be that individuals with a high achievement motive are characterized by high self-control skills, which may protect them from becoming addicted even when their need for competence is thwarted (Schüler \& Kuster, 2011). Thus, a third variable (self-control) is likely to have overridden the expected interaction effect. Again, further empirical evidence is needed to test this assumption generated by the study's results.

Overall, our results are in accordance with previous research demonstrating the positive consequences of basic need satisfaction in sports (Adie et al., 2008; Edmunds et al., 2006; Reinboth \& Duda, 2006; Schüler et al., 2010; Wilson et al., 2003) in that they showed main effects of competence satisfaction on flow (pilot study and main study) and positive affect (pilot study), and of need for relatedness satisfaction on positive affect (pilot study), flow, and negatively on exercise addiction (main study). This speaks in favor of the attempts by SDT researchers to intervene in sport settings in such a way that important psychological needs can be fulfilled. However, our results also show that changing the sport environment (e.g., by giving performance-related feedback and by creating a friendly, harmonious atmosphere) may not be enough; but that, in addition, a differential perspective is needed to predict intrinsic motivation and well-being in sport. By considering implicit motives, it is possible to explain, for example, why some people (e.g., those with 
a low achievement motive) do not respond to changes in the sport environment (e.g., supporting feelings of competence). Other incentives (e.g., supporting feelings of social relatedness) must be created for such individuals.

An important question that has to be answered by future research is whether the effects of the basic need for autonomy - the third basic psychological need in SDT-are also moderated by a corresponding motive. Motive disposition research in the tradition of McClelland (1985) has focused on the motive triad of achievement, affiliation, and power motives and has not suggested a dispositional counterpart to the need for autonomy, which would be an "autonomy motive." Researchers might, for example, test the "freedom" motive proposed in Kuhl and Scheffer's (1999) motive measure (Operant Motive Test) or even earlier measures of origin (deCharms \& Plimpton, 1992) as moderators of potential need for autonomy satisfaction $\times$ autonomy motive interaction effects on flow and well-being.

Another theoretically and methodological interesting question is, "What do our results say about the universality of basic needs?" They suggest that the effects of basic need satisfaction are not "universal" but are influenced by personality variables (implicit motives). However, this statement too needs to be considered with caution: In the present studies, we used a basic psychological need satisfaction measure (Sheldon \& Hilpert, 2012) that-as is customary when measuring need satisfaction (e.g., Basic Satisfaction of Needs Scale, Gagné, 2003) - assesses a sense of competence/achievement (e.g., I took on and mastered hard challenges; I successfully completed difficult tasks and projects) and relatedness/affiliation (e.g., I felt a sense of connection with people who care for me, and whom I care for; I felt close and connected to other people who are important to me) rather than assessing need satisfaction directly. Based on this current state-of-the-art basic need satisfaction measurement and adopting the perspective of the motive disposition approach, the need satisfaction items represent incentives (in the terminology of McClelland, 1985) for the implicit achievement and affiliation motives. Therefore, the significant interactions found in our studies also confirm a proposition of implicit motive theory. Choosing our words carefully when answering the question of what our results say about the universality of basic needs, it can be said that the effects of basic need satisfaction - as currently measured in basic need satisfaction research-are not equally strong for everybody but are moderated by the corresponding implicit motives.

A practical implication of the studies' findings is that either a motive-sport environment fit has to be created (e.g., through individual sport counseling) to enhance the athletes' motivation and well-being, or the interventions designed to enrich the sport environment have to be diverse so that they are able to fulfill the three basic needs equally.

Finally, we would like to point out that it is worth analyzing individual motive differences if one is interested in the outcomes of basic need satisfaction in sport.

\section{Notes}

1. Because SDT researchers might be interested in oftenreported overall measures of basic need satisfaction and their relationship with well-being, we have in the following reported the correlations between an overall need satisfaction measure (mean of all three basic needs) and our outcome variables. The overall measure of basic need satisfaction in our pilot study was positively (however not significantly, due to the small sample size) correlated with flow, $r=.24, p=.22$, and with positive affect, $r=.31, p=.15$. In the main study, the correlation between overall need satisfaction and flow was significant, $r=.27, p$ $<.01$. In accordance with our interpretation (outlined in the general discussion) that different domains of need satisfaction (and motive interactions) may predict different outcomes, need for relatedness satisfaction, $r=-.24, p<.05$, but not overall need satisfaction, $r=-.16, p=.12$, was significantly correlated with exercise addiction.

2. Only 20 out of 93 participants were women, which reflects the proportion of men to women in extreme endurance sports very well (Knechtle, Knechtle, \& Lepers, 2011); however, the number of women in extreme endurance sports has increased in recent years (Meili, Knechtle, Rüst, Rosemann, \& Lepers, 2013). Because women were, on average, slower than men in extreme endurance sport performance (Rüst, Knechtle, Rosemann, \& Lepers, 2013), it might be that only women with a very high achievement motive reach this top level of sports performance. As the participants' gender did not substantially affect the results of the studies, we will in the following report the results based on the overall sample.

\section{References}

Adie, J.W., Duda, J.L., \& Ntoumanis, N. (2008). Autonomy support, basic need satisfaction, and the optimal functioning of adult male and female sport participants: A test of basic needs theory. Motivation and Emotion, 32, 189-199. doi:10.1007/s11031-008-9095-z

Adie, J.W., Duda, J.L., \& Ntoumanis, N. (2012). Perceived coach-autonomy support, basic need satisfaction and the well- and ill-being of elite youth soccer players: A longitudinal investigation. Psychology of Sport and Exercise, 13, 51-59. doi:10.1016/j.psychsport.2011.07.008

Aube, C., Brunelle, E., \& Rousseau, V. (2014). Flow experience and team performance: The role of team goal commitment and information exchange. Motivation and Emotion, 38(1), 120-130. doi:10.1007/s11031-013-9365-2

Brunstein, J.C. (2008). Implicit and explicit motives. In H. Heckhausen \& J. Heckhausen (Eds.), Motivation and action (pp. 227-246). Cambridge, UK: Cambridge University Press.

Brunstein, J.C., \& Hoyer, S. (2002). Implizites und explizites Leistungsstreben: Befunde zur Unabhängigkeit zweier Motivationssysteme [Implicit versus explicit achievement strivings: Empirical evidence of the independence of two motivational systems]. Zeitschrift fur Padagogische Psychologie, 16, 51-62. doi:10.1024//10100652.16.1.51 
Cohen, P., Cohen, J., West, S.G., \& Aiken, L.S. (2003). Applied multiple regression/correlation analysis for the behavioral sciences (3rd ed.). Hillsdale, NJ: Erlbaum.

Csikszentmihalyi, M. (1990). Flow: The psychology of optimal experience. New York: Harper \& Row.

Csikszentmihalyi, M., \& LeFevre, J. (1989). Optimal experience in work and leisure. Journal of Personality and Social Psychology, 56, 815-822. PubMed doi:10.1037/00223514.56.5.815

deCharms, R., Morris, H.W., Reitman, W., \& McClelland, D.C. (1955). Behavioral correlates of directly and indirectly measured achievement motivation. In D.C. McClelland (Ed.), Studies in motivation (pp. 414-423). New York, NY: Appleton-Century-Crofts.

deCharms, R., \& Plimpton, F. (1992). The origin scoring system. In C.P. Smith (Ed.), Motivation and personality: Handbook of thematic content analysis (pp. 334-375). Cambridge, UK: Cambridge University Press.

Deci, E.L., \& Ryan, R.M. (1985). Intrinsic motivation and self-determination in human behavior. New York, NY: Plenum Press.

Deci, E.L., \& Ryan, R.M. (2000). The "what" and "why" of goal pursuits: Human needs and the self-determination of behavior. Psychological Inquiry, 11, 227-268. doi:10.1207/S15327965PLI1104_01

Edmunds, J., Ntoumanis, N., \& Duda, J.L. (2006). A test of self-determination theory in the exercise domain. Journal of Applied Social Psychology, 36, 2240-2265. doi:10.1111/j.0021-9029.2006.00102.x

French, E.G., \& Chadwick, I. (1956). Some characteristics of affiliation motivation. Journal of Abnormal Psychology, 52, 296-300. PubMed doi:10.1037/h0045251

Gagné, M. (2003). The role of autonomy support and autonomy orientation in prosocial behavior engagement. Motivation and Emotion, 27, 199-223. doi:10.1023/A:1025007614869

Griffiths, M.D. (1996). Behavioural addiction: An issue for everybody? Journal of Workplace Learning, 8(3), 19-25. doi:10.1108/13665629610116872

Hausenblas, H.A., \& Downs, D.S. (2002). Exercise dependence: A systematic review. Psychology of Sport and Exercise, 3, 89-123. doi:10.1016/S1469-0292(00)00015-7

Jackson, S.A., Ford, S.K., Kimiecik, J.C., \& Marsh, H.W. (1998). Psychological correlates of flow in sport. Journal of Sport \& Exercise Psychology, 20, 358-378.

Knechtle, B., Knechtle, P., \& Lepers, R. (2011). Participation and performance trends in ultra-triathlons from 1985 to 2009. Scandinavian Journal of Medicine \& Science in Sports, 21(6), e82-90. PubMed doi:10.1111/j.16000838.2010.01160.x

Krohne, H.W., Egloff, B., Kohlmann, W., \& Tausch, A. (1996). Untersuchungen mit einer deutschen Version der PANAS [Research with a German version of the PANAS]. Diagnostica, 44, 139-156.

Kuhl, J., \& Scheffer, D. (1999). Der operante Multi-Motive-Test (OMT): Manual. [The operant multi-motive-test (OMT): Manual]Germany: University of Osnabrück. [The operant multi-motive-test (OMT): Manual].

Luyckx, K., Vansteenkiste, M., Goossens, L., \& Duriez, B. (2009). Basic need satisfaction and identity formation:
Bridging self-determination theory and process-oriented identity research. Journal of Counseling Psychology, 56, 276-288. doi:10.1037/a0015349

McClelland, D.C. (1979). Inhibited power motivation and high blood pressure in men. Journal of Abnormal Psychology, 88, 182-190. PubMed doi:10.1037/0021-843X.88.2.182

McClelland, D.C. (1985). Human motivation. Glenview, IL: Scott, Foresman.

McClelland, D.C., Atkinson, J.W., Clark, R.A., \& Lowell, E.L. (1953). The achievement motive. New York, NY: AppletonCentury-Crofts.

McClelland, D.C., Koestner, R., \& Weinberger, J. (1989). How do self-attributed and implicit motives differ? Psychological Review, 96(4), 690-702. doi:10.1037/0033295X.96.4.690

Meili, D., Knechtle, B., Rüst, C.A., Rosemann, T., \& Lepers, R. (2013). Participation and performance trends in "Ultraman Hawaii" from 1983 to 2012. Extreme Physiology and Medicine, 2(1), 25. PubMed doi:10.1186/2046-7648-2-25

Murray, H.A. (1938). Explorations in personality. New York, NY: Wiley.

Murray, H.A. (1943). Thematic apperception test manual. Cambridge, MA: Harvard University Press.

Nakamura, J., \& Csikszentmihalyi, M. (2002). The concept of flow. In C.R. Snyder \& S.J. Lopez (Eds.), Handbook of positive psychology (pp. 89-105). Oxford, UK: Oxford University Press.

Reinboth, M., \& Duda, J.L. (2006). Perceived motivational climate, need satisfaction and indices of well-being in team sports: A longitudinal perspective. Psychology of Sport and Exercise, 7(3), 269-286. doi:10.1016/j.psychsport.2005.06.002

Rheinberg, F., Manig, Y., Kliegl, R., Engeser, S., \& Vollmeyer, R. (2007). Flow bei der Arbeit, doch Glück in der Freizeit. Zielausrichtung, Flow und Glücksgefühle [Flow during work but happiness during leisure time: Goals, flow experience, and happiness]. Zeitschrift für Arbeits- und Organisationspsychologie, 51, 105-115. doi:10.1026/0932-4089.51.3.105

Rheinberg, F., Vollmeyer, R., \& Engeser, S. (2003). Die Erfassung des Flow-Erlebens. In J. Stiensmeier-Pelster \& F. Rheinberg (Eds.), Diagnostik von Selbstkonzept, Lernmotivation und Selbstregulation (pp. 261-279). Göttingen, Germany: Hogrefe.

Rüst, C.A., Knechtle, B., Rosemann, T., \& Lepers, R. (2013). Men cross America faster than women-The "Race Across America" from 1982 to 2012. International Journal of Sports Physiology and Performance, 8(6), 611-617. PubMed

Ryan, R.M., \& Deci, E.L. (2000). The darker and brighter sides of human existence: Basic psychological needs as a unifying concept. Psychological Inquiry, 11, 319-338. doi:10.1207/S15327965PLI1104_03

Schiepe-Tiska, A., \& Engeser, S. (2012). Flow in nonachievement situations. In S. Engeser (Ed.), Advances in flow research (pp. 87-107). New York, NY: Springer.

Schüler, J. (2007). Arousal of flow-experience in a learning setting and its effects on exam-performance and affect. Zeitschrift fur Padagogische Psychologie, 21, 217-227. doi:10.1024/1010-0652.21.3.217 
Schüler, J., \& Brandstätter, V. (2013). How basic need satisfaction and dispositional motives interact in predicting flow experience in sport. Journal of Applied Social Psychology, 43(4), 687-705. doi:10.1111/j.15591816.2013.01045.x

Schüler, J., Brandstätter, V., \& Sheldon, K.M. (2013). Do implicit motives and basic psychological needs interact to predict well-being and flow? Testing a universal hypothesis and a matching hypothesis. Motivation and Emotion, 37(3), 480-495. doi:10.1007/s11031-012-9317-2

Schüler, J., \& Kuster, M. (2011). Binge eating as a consequence of unfulfilled basic needs: The moderating role of implicit achievement motivation. Motivation and Emotion, 35, 89-97. doi:10.1007/s11031-010-9200-y

Schüler, J., Sheldon, K.M., \& Fröhlich, S.M. (2010). Implicit need for achievement moderates the relationship between felt competence and subsequent motivation. Journal of Research in Personality, 44, 1-12. doi:10.1016/j. jrp.2009.09.002

Schultheiss, O.C. (2001). An informational processing account of implicit motive arousal. In M. L. Maehr \& P. Pintrich (Eds.), Advances in motivation and achievement (Vol.12: New directions in measures and methods, pp. 1-41). Greenwich, CT: JAI Press.

Schultheiss, O.C., \& Brunstein, J.C. (2010). Implicit motives. New York, NY: Oxford University Press.

Schultheiss, O.C., \& Hale, J. (2007). Implicit motives modulate attentional orienting to facial expressions of emotion. Motivation and Emotion, 31, 13-24. doi:10.1007/s11031006-9042-9

Schultheiss, O.C., Liening, S., \& Schad, D. (2008). The reliability of a picture story exercise measure of implicit motives: Estimates of internal consistency, retest reliability, and ipsative stability. Journal of Research in Personality, 42, 1560-1571. doi:10.1016/j.jrp.2008.07.008

Schultheiss, O.C., \& Pang, J.S. (2007). Measuring implicit motives. In R.W. Robins, R.C. Fraley, \& R. Krueger (Eds.), Handbook of research methods in personality psychology (pp. 322-344). New York, NY: Guilford.
Schultheiss, O.C., Wirth, M.M., Torges, C.M., Pang, J.S., Villacorta, M.A., \& Welsh, K.M. (2005). Effects of implicit power motivation on men's and women's implicit learning and testosterone changes after social victory and defeat. Journal of Personality and Social Psychology, 88(1), 174-188. PubMed doi:10.1037/0022-3514.88.1.174

Sheldon, K.M., \& Hilpert, J.C. (2012). The balanced measure of psychological needs (BMPN) scale: An alternative domain general measure of need satisfaction. Motivation and Emotion, 36, 439-451. doi:10.1007/s11031-012-9279-4

Terry, A., Szabo, A., \& Griffiths, M. (2004). The exercise addiction inventory: A new brief screening tool. Addiction Research and Theory, 12(5), 489-499. doi:10.1080/1606 6350310001637363

Vansteenkiste, M., Niemiec, C., \& Soenens, B. (2010). The development of the five mini-theories of self-determination theory: An historical overview, emerging trends, and future directions. In T. Urdan \& S. Karabenick (Eds.). Advances in Motivation and Achievement, vol. 16: The decade ahead (pp. 105-166). Bingley, UK: Emerald Publishing.

Weinberger, J., \& McClelland, D.C. (1990). Cognitive versus traditional motivational models? Irreconcilable or complementary? In E.T. Higgins \& R.M. Sorrentino (Eds.), Handbook of motivation and cognition (Vol. 2, pp. 562-597). New York, NY: Guilford.

Wilson, P.M., Rodgers, W.M., Blanchard, C.M., \& Gessell, J. (2003). The relationship between psychological needs, self-determined motivation, exercise attitudes, and physical fitness. Journal of Applied Social Psychology, 33, 2373-2392. doi:10.1111/j.1559-1816.2003.tb01890.x

Winter, D.G. (1973). The power motive. New York, NY: The Free Press.

Winter, D.G. (1994). Manual for scoring motive imagery in running text. Unpublished instrument. Ann Arbor: University of Michigan.

Zaryski, C., \& Smith, D.J. (2005). Training principles and issues for ultra-endurance athletes. Current Sports Medicine Reports, 4(3), 165-170. PubMed doi:10.1097/01. CSMR.0000306201.49315.73

Manuscript submitted: August 28, 2013

Revision accepted: March 23, 2014 